\title{
Children and parents' perspectives of the impact of the COVID-19 pandemic on Ontario children's physical activity, play, and sport behaviours
}

Monika Szpunar', Leigh M. Vanderloo 1,2, Brianne A. Bruijns', Stephanie Truelove', Shauna M. Burke 1,3,4, Jason Gilliland ${ }^{4,5}$, Jennifer D. Irwin ${ }^{1,3}$ and Patricia Tucker ${ }^{1,2,4^{*}}$

\begin{abstract}
Background: The COVID-19 pandemic and associated public health measures have resulted in the closure of many physical activity-supporting facilities. This study examined Ontario parents' and children's perspectives of COVID-19's impact on children's physical activity behaviours, return to play/sport during COVID-19, as well as barriers/facilitators to getting active amid extended closures of physical activity venues.
\end{abstract}

Methods: Parents/guardians of children aged 12 years and under living in Ontario, Canada were invited to participate in an interview. 12 parent/guardian and 9 child interviews were conducted via Zoom between December 2020 January 2021, were audio-recorded, and transcribed verbatim. Thematic content analysis was undertaken to identify pronounced themes.

Results: Themes for both parent and child interviews fell into one of three categories: 1) barriers and facilitators for getting children active amid COVID-19 closures of physical activity-supporting facilities; 2) changes in children's activity levels; and, 3) perspectives on return to play/sport during and post-pandemic. Various subthemes were identified and varied between parents and children. The most common facilitator for dealing with children's inactivity voiced by parents/guardians was getting active outdoors. Parents/guardians noted their willingness to have their children return to play/sport in the community once deemed safe by public health guidelines, and children's willingness to return stemmed primarily from missing their friends and other important authority figures (e.g., coaches) and sporting events (e.g., tournaments).

Conclusions: Findings from this study could inform families of feasible and realistic strategies for increasing children's physical activity during community closures, while also providing public health experts with information regarding what supports, or infrastructure might be needed during future lockdown periods and/or pandemics.

Keywords: Physical activity, COVID-19, Children, Physical distancing

*Correspondence: ttucker2@uwo.ca

${ }^{4}$ Children's Health Research Institute, Lawson Health Research Institute, London, Ontario, Canada

Full list of author information is available at the end of the article

\section{Background}

During childhood (0-12 years), children often explore various forms of movement via activities such as sports, playing outdoors, and engaging in play with others [1] These activities are very important for children in their developing years, as engagement in sport and/or 
unstructured play often leads to higher levels of moderate-to-vigorous-intensity physical activity (MVPA), which is associated with numerous health benefits [2, 3]. In fact, the Canadian 24-Hour Movement Guidelines advocate that children aged 3-12years should achieve at least 60-min per day of MVPA per day [4] as this supports various aspects of health, including psychosocial and mental health outcomes [2], the development of motor and fundamental movement skills [4], and stronger immune systems [5]. Collectively, there is growing research to suggest that children who meet guidelines possess better overall health compared to those who do not [4].

On March 11, 2020, the World Health Organization (WHO) declared COVID-19 a global pandemic [6]. Due to COVID-19's high transmission rates, many countries, including Canada, enforced multiple public health measures such as physical distancing (e.g., maintaining a distance of $2 \mathrm{~m}$ from others), mandatory masking, and lockdowns periods (e.g., requiring citizens to stay home) to reduce the spread of the virus [7] . Specifically in Ontario, these rules included many additional prohibitions, including, but not limited to: bans on indoor and outdoor gatherings; closures of facilities where people regularly gather (e.g., community centres, gyms, parks, trails, shopping malls); and, closures of schools and other large institutions (i.e., workplaces and non-essential businesses [8];). These new rules, regulations, and policies led to the restructuring and/ or termination of many activities that previously supported physical activity for individuals of all ages, including children [9]. For example, organized sports were cancelled for many months (i.e., March - September 2020; November 2020 - April 2021 [8];) in staggered formats (i.e., re-opened in certain jurisdictions across Ontario as case counts dropped) due to their increased likelihood of having multiple individuals in close proximity, and outdoor play spaces (e.g., parks, splash pads) were closed to prevent large gatherings [9]. As a result, from March 2020 - January 2021 (data collection for the larger "Return to Play" study), many children and their families no longer had access to typical physical activity-supporting environments and programming, thus resulting in many barriers to ensuring children were sufficiently active each day. Moreover, over the last 18 months, the government of Ontario has adopted various re-opening strategies; however, at the time of data collection, a colour coding system was in place [8]. For example, Ontario jurisdictions were categorized as being either in the grey, red, orange, yellow or green-zones, dependent on the number of active COVID-19 cases in the area [8]. Colours were used to inform citizens about the activities that were allowed and/or prohibited, and to keep jurisdictions aware of the risk in their respective communities.

Prior to the COVID-19 pandemic, the proportion of Canadian children meeting national integrative movement behaviour guidelines (i.e., physical activity, sedentary behaviour, and sleep) was already problematic. In fact, only $\sim 13 \%$ of Canadian children aged 3-4 years and 5-12 years were meeting their respective age-specific guidelines $[10,11]$. Unfortunately, these low rates have been further compromised by the pandemic recent data from early pandemic days (i.e., April 2020) showed that only $2.8 \%$ of Canadian children were meeting the 24-Hour Movement Guidelines [12]. Moreover, preliminary findings have demonstrated the negative impact of COVID-related lockdowns and closures of outdoor spaces on Canadian children's physical activity opportunities [12] and levels [13]. For example, Moore and colleagues' study found a dramatic decline in children's outdoor physical activity, and drastic increase in screen time and social media use [12]. Similarly, Bates and colleagues' [13] commentary also reported significant decreases in physical activity, increases in sedentary time, and sleep disruptions among children aged 5-17 years. These trends are apparent worldwide, as studies in Italy [14], South Korea [15], Shanghai [16], and the United States [17] have reported similar behavioural shifts among children during COVID-19. Undoubtedly, lockdowns and closures of physical activity-supportive spaces, despite their positive role in helping to curb the spread of the virus, have also had negative impacts on children's movement behaviours and have posed difficulties for parents and guardians who are trying to support their children's health.

To date, limited qualitative studies are available examining how the COVID-19 pandemic has impacted families and children as it relates to physical activity [18]. Further missing from the literature are children's voices. More specifically, a lack of information exists regarding children's perspectives about getting active during COVID-19, their experienced barriers, as well as the facilitators implemented by this young cohort. Thus, the primary purpose of this study was to explore Ontario parents' and children's perspectives of the COVID-19 pandemic's impact on children's physical activity behaviours, perspectives on return to play/sport, as well as the barriers and facilitators to getting active amid extended closures of physical activity venues.

\section{Methods}

\section{Study design}

This study was part of a larger cross-sectional study, entitled 'Return to Play', which quantitatively assessed the perspectives of parents during the pandemic (i.e., 
August - December 2020) regarding their children's physical activity levels, their intentions to resume sports and physical activities post-pandemic and their risk tolerance. To solicit richer, contextual data, the present study captured qualitative data via interviews about physical activity participation during the pandemic from a pool of survey participants who expressed interest in participating in online Zoom interviews. The Western University Non-Medical Research Ethics Board approved all study procedures and associated documents (REB \#116331).

\section{Recruitment and participants}

Parent participants were eligible to participate if they were a parent or guardian of a child 12 years old or younger, resided in Ontario, had custody of their child(ren) at least $50 \%$ of the time, and participated in the larger study (i.e., online survey). Upon completion of the survey, participants were asked if they were interested in participating in an internet-based interview (i.e., audio only, conducted via Zoom) to further share their perspectives on their children's return to physical activity-related programming post-COVID-19, and activity levels during COVID. A total of 1097 parents completed the online survey and were included in the original study, and 392 parents expressed their interest in participating in a follow-up interview. Using www.randomizer.org, parents were randomly selected from the 392 volunteers and were invited via email to participate in an interview. At this time, parents were also notified that their children were invited to participate, if interested. Only children that met the inclusion criteria (i.e., 12 years of age or under, living in Ontario, had a parent who completed the online survey, and spoke English) were eligible. If participants did not respond to the email within one week, the next randomly selected participant was contacted and invited. A total of 32 parents and their children were invited to participate. Recruitment continued until saturation was achieved.

\section{Interview procedures}

Data collection occurred between December 2020 and January 2021. All parent interviews were $30-45 \mathrm{~min}$ in length and were recorded via the online video platform, Zoom. Child interviews were completed subsequently to parent interviews if from the same household, or uniquely if not (i.e., parent who completed the online survey organized a time via email for their child's interview to take place with the research assistant). Dependent on the age of the child, a parent was sometimes present for the duration of the interview. All child interviews ranged between $10-25 \mathrm{~min}$ in length. Only audio content for both parent and child interviews were recorded. Individual interview guides were created by the research team for parent and child participants. Parents/guardians were asked to provide verbal consent at the start of interviews, and verbal assent from children was also obtained. Member checking (i.e., restating or summarizing information for the purpose of determining correctness) was used by the research assistant conducting interviews to ensure accuracy of participant responses [19], verify the trustworthiness of qualitative results [20] and ensure credibility [21]. Interviews were digitally transcribed verbatim using QSR NVivo (version 12). Two trained research assistants confirmed the transcripts for accuracy using NVivo. Upon completion of each interview, participants were given token of appreciation for their time. Please see Additional file 1: Appendix A and B for the parent and child semi-structured interview guides, respectively.

\section{Analysis}

All interviews were analyzed using QSR NVivo (version 12). Thematic content analysis was conducted by two trained researchers to ensure confirmability and to identify common participant responses [22, 23]; specifically, the records of all transcripts coding processes were documented, to ensure a logical and traceable approach [21]. In addition, intercoder reliability was assessed using reliability checks during the analysis period (e.g., reviewing evidence and debriefing [22];), and comparing codes in Nvivo. Because the interviews were conducted using semi-structured interview guides, transcripts from parent and child interviews were analyzed separately and responses were grouped based on each question and analyzed deductively. Thematic analyses were conducted in accordance with Braun and Clarke's best practices [23]: (1) read through all interview transcripts to become familiar with the data, reviewing the content repeatedly; (2) generate a list of codes based on items found in the data sets, and colour-coded items manually when patterns emerged; (3) analyze codes and identified prominent themes and subthemes; (4) review the themes; (5) identify proper names for themes; and, (6) present interview data via tables and written summaries of the themes and subthemes using quotes. Deductive content analysis was used to test existing categories, and concepts that became apparent to the research assistants from responses to open-ended questions in the online survey. Confirmation bias was avoided as the secondary coder was only responsible for coding interviews and was not directly involved in the project [24]. Having two independent coders prevented the occurrence of having the research team form a hypothesis or belief and using the respondents' information to confirm that belief. 


\section{Results}

A total of 12 parents/guardians and 9 children from across Ontario participated in interviews. Nearly all ( $n=11,92 \%)$ of parent participants identified as female and were from urban communities. Parents had an average age of 40.67 years $(S D=7.49)$, and an average of 1.67 children $(S D=0.651)$. Majority $(n=8 ; 67 \%)$ of parents lived in semi-detached or detached homes. Child participants were mostly female $(n=6,67 \%)$, had an average age of 7.33 years $(S D=2.92)$, and all resided in urban environments across Ontario. See Table 1 for full participant characteristics.

Analyses revealed four over-arching themes which were apparent in both parent and child interviews, and were consistent with the questions from the semi-structured interview guides: (1) barriers associated with children getting active during COVID-19-related closures; (2) facilitators used to encourage children to become active during COVID-19 closures; (3) perspectives on returning to organized sport and/or engaging in physical activity involving social interaction with others during (e.g., when

Table 1 Participant Characteristics of Parents/Guardians $(n=12)$ and Children $(n=9)$ in Ontario

\begin{tabular}{|c|c|c|c|c|}
\hline \multirow[t]{2}{*}{ Participant Characteristics } & \multicolumn{2}{|c|}{$\begin{array}{l}\text { Parents/ } \\
\text { Guardians }\end{array}$} & \multicolumn{2}{|c|}{ Children } \\
\hline & $M$ & $S D$ & $M$ & $S D$ \\
\hline \multirow[t]{2}{*}{ Age (years) } & 40.67 & 7.50 & 7.33 & 2.91 \\
\hline & $N$ & $\%$ & $N$ & $\%$ \\
\hline \multicolumn{5}{|l|}{ Gender } \\
\hline Male & 1 & 8.3 & 3 & 33.3 \\
\hline Female & 11 & 91.7 & 6 & 66.7 \\
\hline \multicolumn{5}{|l|}{ Community Type } \\
\hline Urban & 11 & 91.7 & 9 & 100.0 \\
\hline Rural & 1 & 8.3 & - & - \\
\hline \multicolumn{5}{|c|}{ Colour/Phase Re-Opening (at time of interview) } \\
\hline Yellow & 1 & 8.3 & - & - \\
\hline Orange & - & - & 1 & 11.1 \\
\hline Red & 5 & 41.7 & 3 & 33.3 \\
\hline Grey (Lockdown) & 6 & 50.0 & 5 & 55.6 \\
\hline \multicolumn{5}{|l|}{ Housing Type } \\
\hline Apartment/Condominium & 2 & 16.7 & 1 & 11.1 \\
\hline Detached or semi-detached house & 8 & 66.6 & 7 & 77.8 \\
\hline $\mathrm{N} / \mathrm{A}$ & 2 & 16.7 & 1 & 11.1 \\
\hline \multicolumn{5}{|l|}{ Number of Children } \\
\hline 1 & 5 & 41.7 & - & - \\
\hline 2 & 6 & 50.0 & - & - \\
\hline 3 & 1 & 8.3 & - & - \\
\hline
\end{tabular}

Note. Colour/Phase Re-Opening refers to the current state of Ontario's re-opening plan at the time of data collection (i.e., December 2020 - January 2021). Please see https://www.toronto.com/news-story/10239506-here-s-howontario-s-covid-19-colour-codes-work/ for more information permitted in Ontario; physical distancing and wearing personal protective equipment); and, (4) changes in children's physical activity levels during COVID-19. Unique to parent interviews, two additional themes were social connectedness and lack of regular access to sport and supportive environments (e.g., parks, playgrounds). See Tables 2 and 3 for sample quotes for each theme and subtheme from parents/guardians and children, respectively.

Salient differences in themes were observed across parent and child interviews (i.e., unique subthemes emerged). For example, with regard to barriers to engaging children in physical activity, parent interviews revealed weather, housing type (e.g., apartment, detached house), screen-time, loss of their previously daily routines, financial barriers, closures of supportive environments, and lack of motivation as subthemes, while children perceived missing important people (i.e., friends, coaches), closure of outdoor play spaces (i.e., parks) and lack of things to do at home as the most notable barriers. In greater detail, many parents reported that screen time became an overwhelmingly large part of children's days, as they had "nothing else to do" while confined at home for extended periods. In addition, finances were mentioned by parents as a barrier towards promoting their children's movement during the deeper stages of the pandemic (i.e., fall of 2020), when the novelty of spending copious amounts of time at home began to ware off. Parents noted this barrier arose as Ontario began to re-open following the first wave (i.e., March - July; 2020 [8];), and sport facilities were permitted to operate at lower capacity. Finances were mentioned with regard to both the purchasing of physical activity-promoting equipment (e.g., trampolines, bikes), as well as the increased cost of sports (when deemed accessible) due to a switch to private lessons, and costs of virtual classes. Finally, the loss of daily routines and lack of parental motivation to support children's activity was frequently noted and was exacerbated by periods of cold weather which posed additional challenges.

With regard to facilitators to getting children active during the pandemic, sample subthemes from parent interviews included: bubbling (i.e., clustering with people outside of immediate household) with other families, spending time outdoors, and using virtual platforms (i.e., Youtube and Tik Tok), of which the latter two were also noted by children. Parents spoke more about the influence of their living space and community (i.e., rural, urban) on their ability to facilitate their children's activity, whereas this was not frequently mentioned by children. Regarding common outdoor spaces, parents with free standing homes that had backyards and other outdoor spaces (i.e., communal living areas, courtyards outside apartments) reported these spaces to be instrumental 


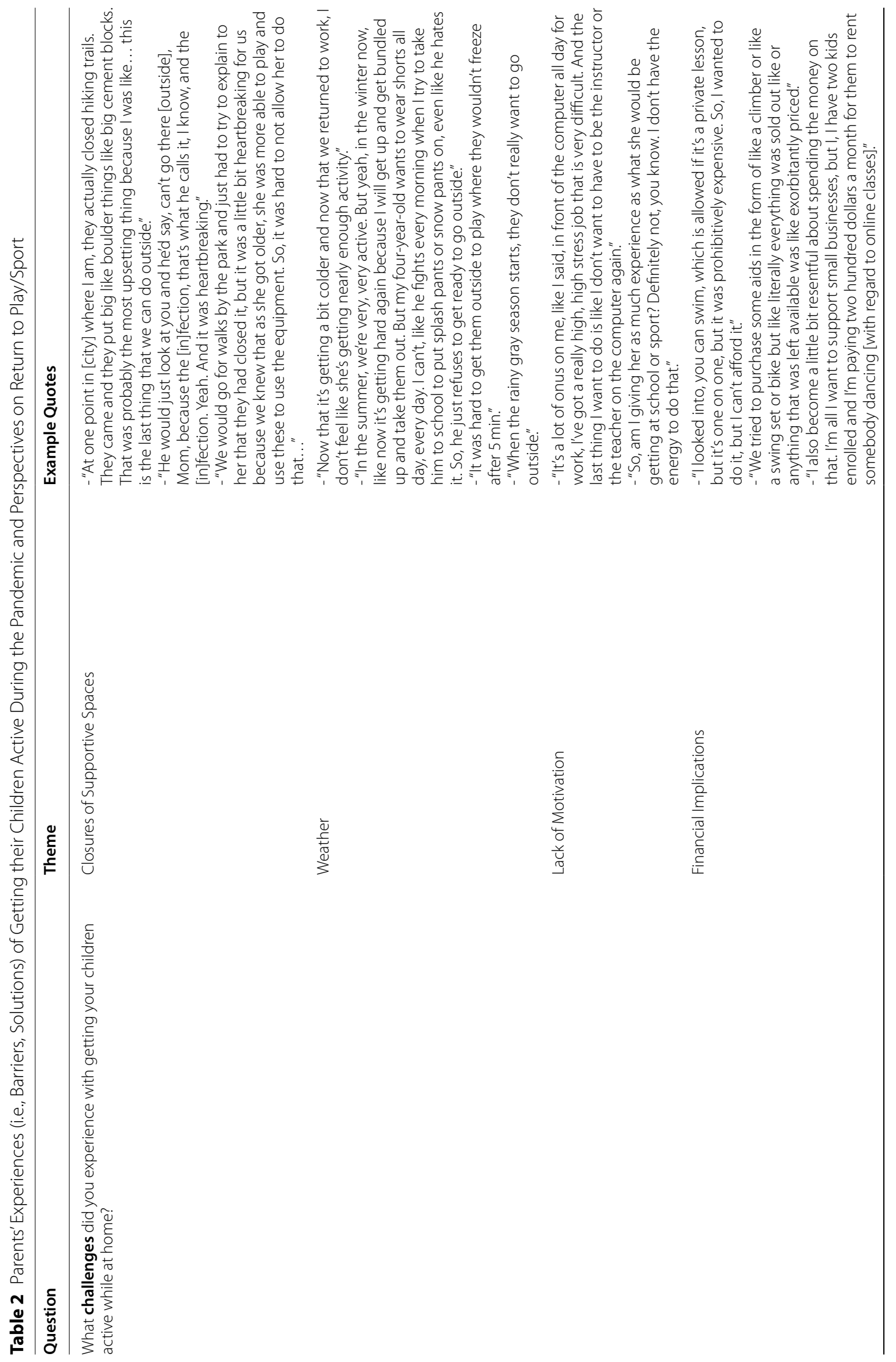




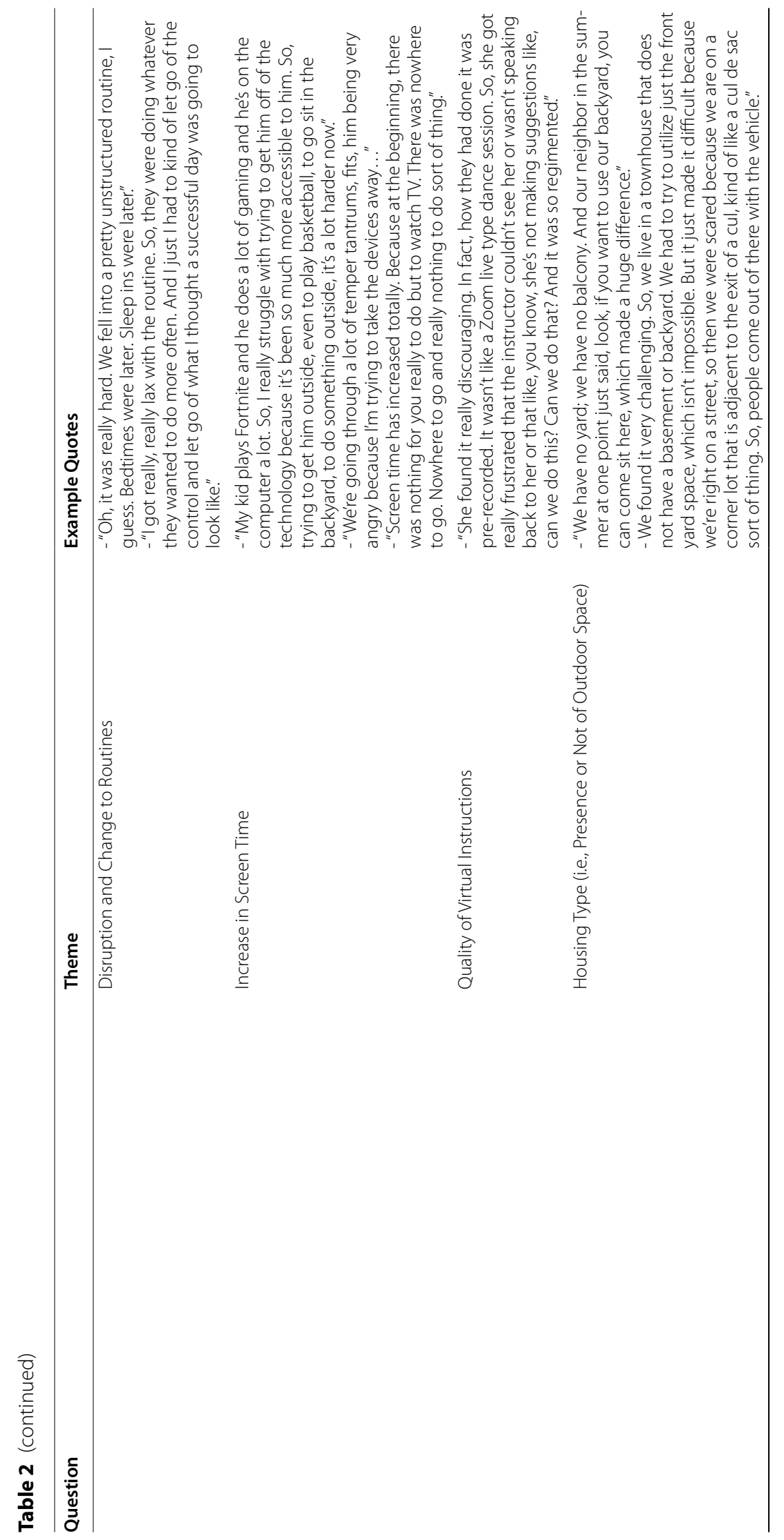




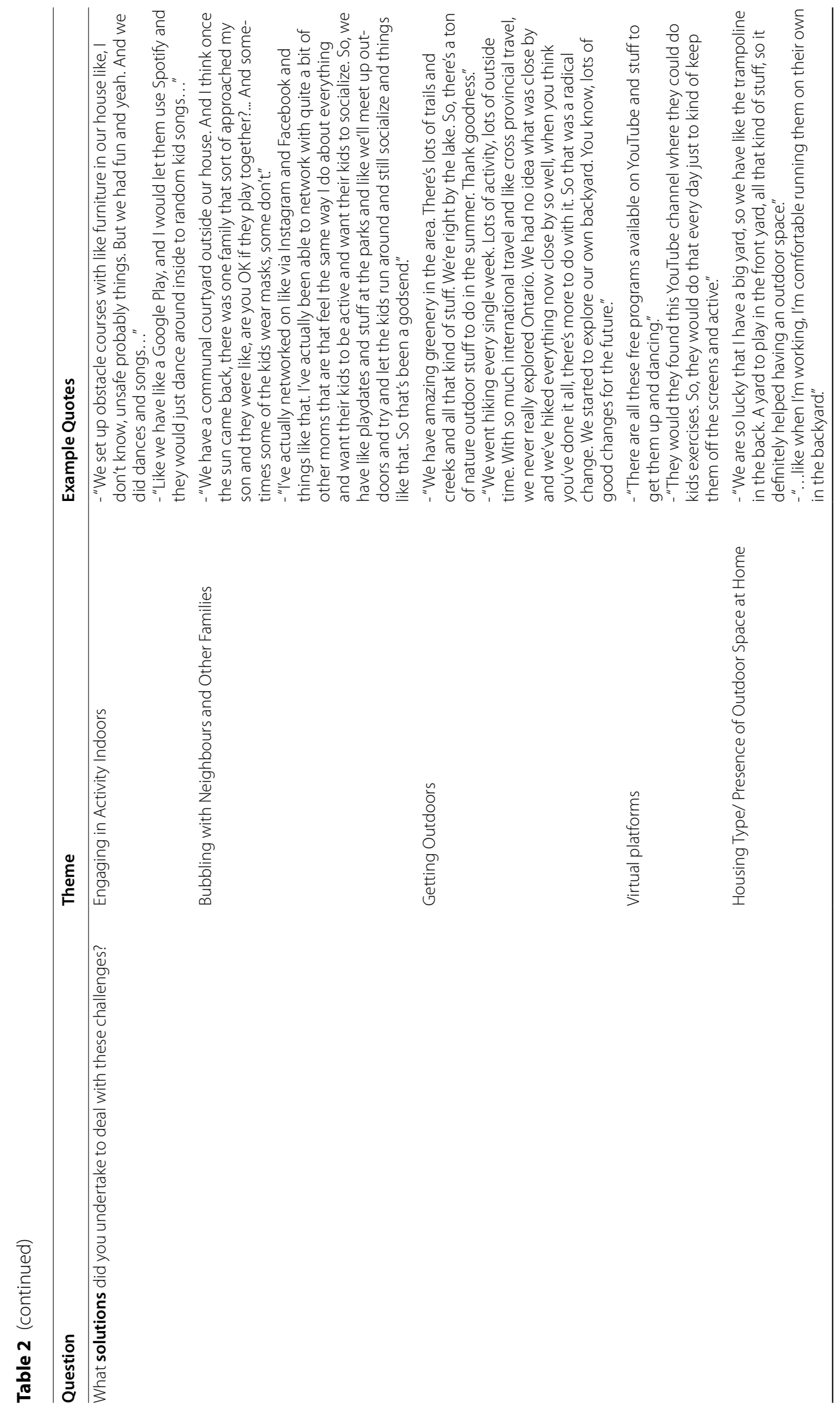




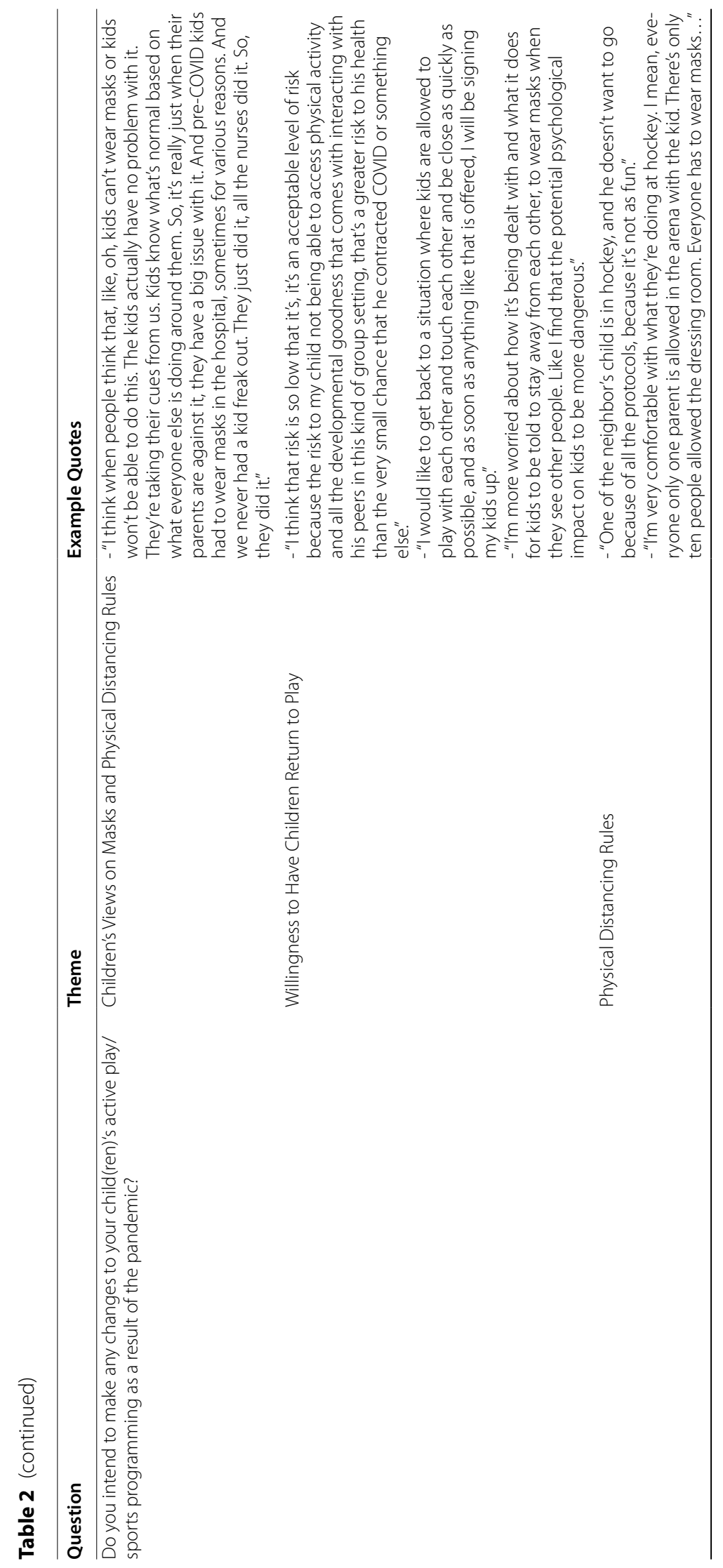




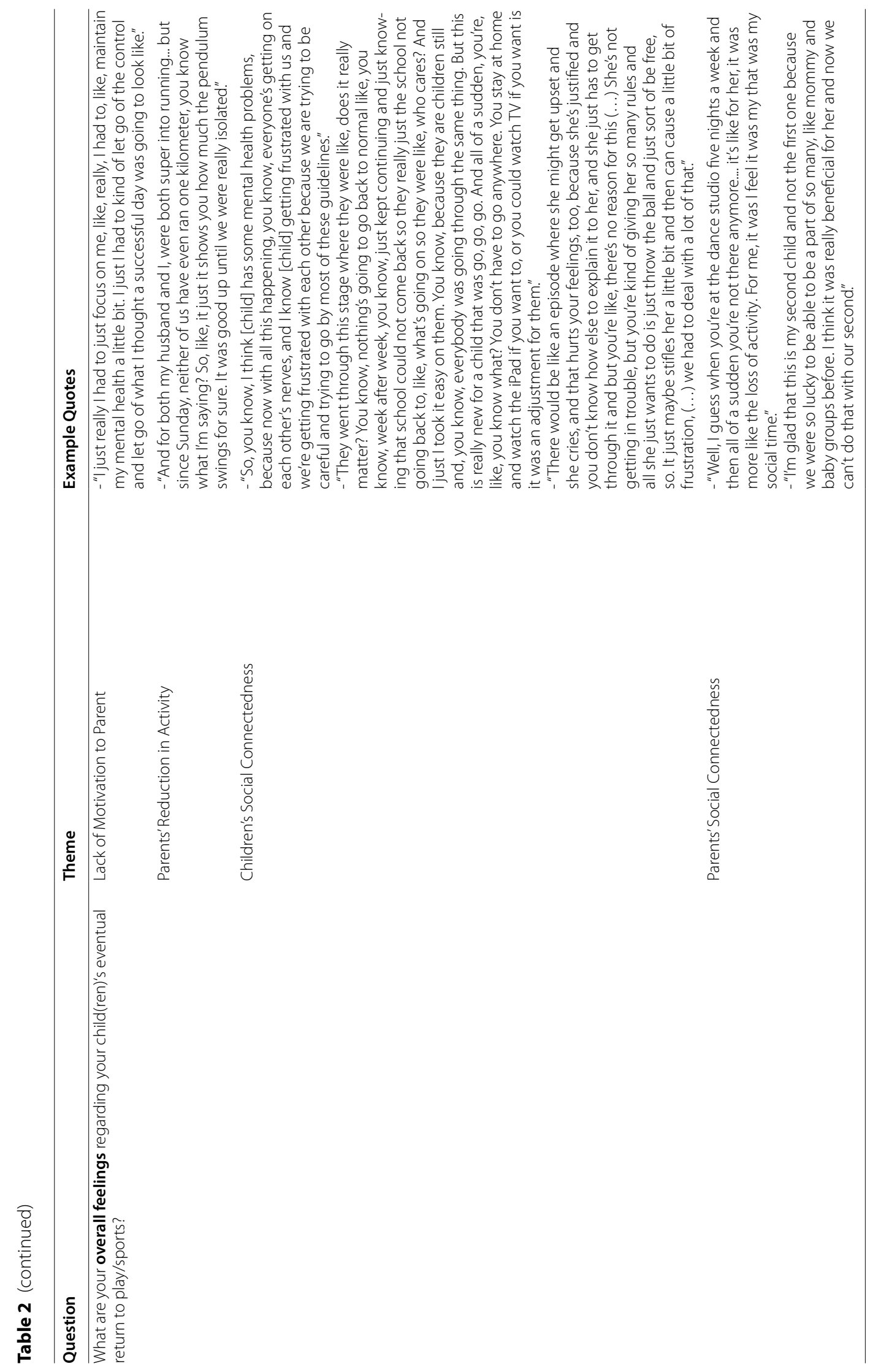


Table 3 Children's Experiences (i.e., Barriers, Solutions) of Getting Active During the Pandemic and Perspectives on Return to Sport

Question

Theme

Not Being Able to See Important Personnel (i.e., Friends, Coaches)

ting active while at home?

What helped you to deal with these challenges? [solutions]

Engaging in a lot of Screen Time
Maintaining Sport or Activity Engagement at Home

Being Able to See Others Outside

Talking to Friends Virtually and on Virtual Platforms

\section{Example Quotes}

- "It impacted me like, very much, because I couldn't see my dance friends. I couldn't go to dance, and I couldn't do much."

- "I was trying to get used to not going outside, not going to the park, and not seeing my friends but it was really hard."

- "I miss seeing my friends and getting to go to competitions or swim meets and just having fun." - "I miss seeing how people can teach me new ways to get better at stuff or like to play with a group of people instead of just one person."

- "I'd pretty much be sitting on my phone talking to my friends all day."

- "We watched a lot of tv shows, YouTube, and TikTok."

- "It's challenging not being able to play with my family because they're like doing work and stuff and because my dad still goes to his job."

Closures of Outdoor Spaces and Sport Facilities - "I can't go on the slide, and they took off? the swing, the monkey bars and the rings."

- "When you get to be in person is much more fun than trying to dance on your own at home when you don't have the studio, or mirrors, or space."

- "I had some online gym classes, and I would go outside and roll out my mat. l'd go on my trampoline, and my friend made me download this workout app so l'd workout with her on the phone."

- "I played hide and seek with my sister. We also played tag, skipping rope, hula hoop and hopscotch."

- "I miss basketball, but me and my mom play basketball together."

- "I have a hockey set-up in my basement, so I play hockey in the basement."

- "When things started to cool down, I would be allowed to go hang out with a few friends that we like, knew parents of."

- "We went and played at parks and at my school. We got outside and built an igloo."

- "I got to see the neighbourhood kids in the summer, and I made some new friends."

- "We made a group chat, and we'll play games together and stuff and talk about what we did what we ate, what we learned online, at school, and asking each other about what all were doing at home."

- "Knowing we were all kind of going through the same thing was helpful. And knowing that it wasn't just me who was missing all of the activities and sports events we had lined up."

- "I used to do dancing online, but it [the internet] was always freezing."

-"I went on hockey training camp on Zoom five days a week, $1 \mathrm{~h}$ per day, for 6 weeks." 
Table 3 (continued)

\begin{tabular}{|c|c|c|}
\hline Question & Theme & Example Quotes \\
\hline \multirow[t]{2}{*}{$\begin{array}{l}\text { Have you and/or your parents/guardians already } \\
\text { made any changes as a result of COVID-19 } \\
\text { to your active play or sport programming? For } \\
\text { example, are you back in any team activities or } \\
\text { planning to go back? }\end{array}$} & Parents as Primary Decision Makers & $\begin{array}{l}\text { - "My mom's thought process was like if were } \\
\text { going back to school, and they want me to keep } \\
\text { my social bubble, I'm already exposed to the same } \\
\text { people. Dance isn't going to be much worse, } \\
\text { because it's going to be the same precautions as } \\
\text { school. And a lot of my dance friends are also from } \\
\text { school." } \\
\text { - "I'm not the one who decides... it's my mom." } \\
\text { - "After corona, I'm planning to go back only if my } \\
\text { mom lets me, and now that its corona, no, I'm not } \\
\text { planning on doing anything." } \\
\text { - "We heard that dance was coming back, and we } \\
\text { just went back. It was like a no brainer." }\end{array}$ \\
\hline & Perspectives on Health Protocols at Sport & $\begin{array}{l}\text { - "It was still super easy with the protocols." } \\
\text { - "I don't mind wearing my mask." } \\
\text { - "It's kind of the same as before besides the } 5 \text { or } \\
\text { 10-min period for them to clean. So instead of } \\
\text { having } 45 \text {-min classes, we had } 35 \text {-min classes, but } \\
\text { we still got the same amount of dance in, we just } \\
\text { had to go a bit faster." } \\
\text { - "It was harder because I kept losing my mask. I } \\
\text { couldn't keep track of it at gymnastics." } \\
\text { - "At hockey, there's a usually a guy waiting at the } \\
\text { door and he's going to ask you questions about if } \\
\text { you were out of the city and if you have any symp- } \\
\text { toms of Covid and then you would go in." }\end{array}$ \\
\hline $\begin{array}{l}\text { Compared to your routine before the pandemic } \\
\text { started (as a reminder, this was in March), do you } \\
\text { think you were more or less active back then } \\
\text { than you are now? }\end{array}$ & Reduction in Activity Levels & $\begin{array}{l}\text { - "I was more active before because with Covid } \\
\text { you can't do very many activities." } \\
\text { - "I miss that I used to be really energetic in dance } \\
\text { and l'm sad I missed my dance recital." } \\
\text {-"I thought I was just going to, like, not be active } \\
\text { enough to go back [to dance]. But I think other } \\
\text { girls felt the same too." } \\
\text {-"I'm less active because we don't have any } \\
\text { games. We're just doing drills." }\end{array}$ \\
\hline
\end{tabular}

in their ability to promote their children's movement. In addition, children who had outdoor play spaces and equipment (i.e., trampolines, yards) that facilitate activity, referenced using them often to maintain their sport skills. Finally, children alluded to getting active with their parents whenever possible, and those who had siblings expressed their engagement of play with them as a facilitator for getting active during stay-at-home orders.

During child interviews, children were most inclined to engage in conversation about what they missed concerning their pre-COVID activities. The most frequently uttered phrase was "I miss my friends". Furthermore, similar to missing friends, children also reported that they missed other important people in their lives, such as their coaches and mentors, and events that come alongside sports (e.g., tournaments). Children reported that they missed their coaches because they felt like their skillset for their sport (i.e., hockey, dance) was falling behind without having constant support and training from someone deemed an "expert". As a result, it was not surprising that nearly all children who had returned to sport at some point prior to interviews, reported having no issues with following health protocols. Children reported that wearing their mask was not a burden, and that returning to sport/play was their priority. Children also commented on enhanced cleaning procedures at their respective sports, not being able to change in changerooms (i.e., coming prepared to sport), and hand sanitizing. Overall, no major concerns were noted by children about health protocols. Similarly, parents reported being satisfied with public health guidelines and health protocols at sports, once they had re-opened, in their respective Ontario cities.

Finally, parents emphasized their loss of social interaction at children's event (i.e., dance lessons, tournaments) as a social connectedness consequence of sport closures, for both themselves and their children. Parents reported that having their children at home for extended periods of time without any social interaction worried them about the impact of the pandemic on their children's social development. In addition, parents reported missing their own time to socialize with other parents 
at their children's sporting events. Finally, with regard to changes in physical activity levels, both parents and children reported that children's levels of physical activity declined during the pandemic. Specifically, it was noted by parents that they felt their children's engagement in MVPA declined, and that they were no longer getting nearly as much heart-pumping or sweat-inducing activity. However, younger children reported being less influenced in regard to their activity levels by COVID-related closures and loss of programming.

\section{Discussion}

The purpose of this study was to explore the perspectives of Ontario parents/guardians and children regarding their experiences getting children physically active during the COVID-19 pandemic, and to examine their feelings concerning children's return to physical activity-related programming. The impact of the pandemic on physical activity levels of children was also explored. Given the timing of the interviews (December 2020 and January 2021), some parents reported that their children had already returned to sport (during a reopening in summer/fall 2020) and were required to follow health protocols (i.e., mask wearing, not being able to access change rooms), while others had not yet returned, as this was dependent on where they were located in the province (i.e., colour phases of re-opening happened at the local level, not provincial [8];). Overall, parents and children provided a great level of detail regarding their experiences during the COVID-19 pandemic. Many themes were identified, and centered around common barriers (e.g., closures of supportive environments), facilitators (e.g., virtual platforms) and perspectives on return to play/sport, including parents' and children's views of new health protocols, lack of motivation to get active during periods of lockdown, and personal protective equipment. It was clear that the pandemic greatly influenced children's movement opportunities and behaviours, as noted by parents and children. Several findings are discussed below.

When asked about challenges regarding children's physical activity participation amid COVID-19 closures, parents frequently referenced the initial stages of the pandemic (i.e., March to May 2020). Parents expressed that these were the most challenging months to encourage behaviours that supported their children's movement, because of the uncertainty associated with engaging in activity outdoors (e.g., potential risk of aerosol transmission at the park), as well as the cold weather in Ontario. Certainly, being confined to one's home and trying to support children's activity while indoors was a commonly noted challenge by parents. In addition, parents who did not have backyards or outdoor space tucked away from major roads voiced their frustration, as they previously relied on parks and/or neighbourhood spaces to safely support their children's movement pre-COVID-19. This is consistent with research conducted prior to the COVID-19 pandemic that supports the impact of the neighbourhood environment on the extent of children's physical activity [25], as well as research comparing urban and rural living environment's effects on physical activity levels of Croatian adolescents during COVID-19 [26]. As most participants in the present study were from urban environments, references to outdoor and indoor spaces and their influence on physical activity offerings were frequently noted. Recently, Zenic and colleagues [26] found a significant influence linking adolescents living in urban environments with lower physical activity levels during the pandemic, compared to their rural counterparts. It is interesting to note that Zenic et al.s [26] findings report that adolescents living in urban settings had physical activity levels that were lower due to their dependence on organized sport for movement, consistent with our findings.

Regarding common outdoor spaces, parents and children with outdoor spaces (e.g., backyards, communal courtyards) reported these spaces to be instrumental in their ability to support movement. Specifically, children who had outdoor play spaces and equipment (i.e., trampolines) that facilitate activity, referenced using them often. This underscores the importance of the home environment, and presence and/or lack of outdoor space during a global pandemic. Consistent with Mitra et al's findings, parents with children aged 5-11 years who lived in an apartment during the pandemic reported that their home space discouraged healthy movement behaviours [27]. In addition, living in neighbourhoods with low density and further from major roads (i.e., highways, large intersections) promoted increased outdoor activity among children [27], and aligns with findings by Nigg and colleagues [28] who found children living in lower density areas exhibited more physical activity during COVID-19. Although the present study only had one participant from a rural environment, this participant noted that their family was not as affected by the closures of supportive environments, as they had their own outdoor playground due to their living space. As a result, according to this parent, living in a rural environment during COVID-19 increased the feasibility to abide by physical distancing, and reduced barriers to accessing outdoor physical activity.

Finances were noted by parents as a barrier for engaging children in activity. Specifically, parents reported sport enrollment during COVID-19 came at a higher cost, likely due to increased health measures in Ontario during phases of re-opening, where less children were 
permitted at a time in various sport facilities (e.g., smaller team sizes), or private lessons becoming the preference, as they were more conducive to physical distancing. In this case, enrollment costs were increased, and parents expressed their frustrations. This represents a possible barrier for future consideration to enrolling children in sport post-COVID (i.e., if costs remain increased as a result of smaller groups due to physical distancing regulations). In addition, the financial aspect of returning to physical activity-related activities post-COVID has also been identified in Australia (Elliott et al. [29],), and has made many parents reference their preference for spending time outdoors or in free, open spaces. Finally, parents emphasized that purchasing home-equipment was a strategy for maintaining their children's activity, but also came with financial implications and budgeting for new toys.

Screen time was another commonly noted barrier to engaging children in activity. This is consistent with Moore and colleagues' findings that showed a drastic increase in social media use during COVID-19 [12] and Riazi et al's study, in which parents reported a drastic increase in their children's screen time, some referencing their children's engagement tripled during various timepoints throughout the pandemic [18]. Interestingly, parents in the present study reported they were "just human" and that an increase in screen time was inevitable as it provided them relief from parental demands, even if just for $30 \mathrm{~min}$. However, some parents also reported increased behavioural issues following removal of screens (e.g., temper tantrums), as children got accustomed to spending majority of their days without other tasks or activities. This is similar to the theme of routine disruptions noted by parents, as without regular programming (i.e., waking up at consistent times for work or school), family routines were irregular or "thrown-off" (e.g., no scheduled "school" hours due to virtual and online learning, more time watching movies, later bedtimes). Similarly, many children reported that they were aware of their increased time spent engaged in screen-viewing during periods of lockdown. Clearly, families spending copious amounts of time at home has led to many changes to daily schedules, including juggling work, parenting, and homeschooling demands, which has consequently, resulted in children engaging in increased amounts of screen-time, alongside a change in typical routines.

Having access to screen-based technology was mentioned by a handful of parent and child participants as a facilitator for activity. Some parents reported allowing their children to follow YouTube tutorials and learn online dances such as those on the social media application called TikTok. The use of virtual platforms identified in the present study is consistent with findings by Moore et al. [12] and Dunton et al. [17] who found remote and streaming services one of the most frequently used mediums by parents to engage children in physical activity during COVID-associated closures. In addition, children referenced various virtual experiences that helped them maintain activity during closures. For example, one child participant mentioned a kid's physical activity smartphone application that provided in-depth at-home workouts and stretching, and other children referenced spending large amounts of time following and/or learning Tik Tok and/or YouTube dance routines with their family members. As a result, screen time seems to have acted as both a barrier and solution for parents and children during the COVID-19 pandemic in Ontario.

Nearly all parent participants reported that they believed their children's activity intensities changed during COVID-19. Specifically, the majority of parent participants stated that they believed their children's engagement in MVPA declined as a result of closures of supportive environments and organized sport, consistent with findings by Moore et al. [12] showing that children's physical activity declined in all forms of activity (i.e., outdoor activity, sports), except for household chores. This is likely due to the time demands of engaging children in this type of activity, as many parents reported that after working long days and juggling at-home tasks (i.e., organizing children's virtual homeschool hours) the last thing that they had energy for was engaging their children in high intensity activity. Specifically, parents noted children's inability to play with other children as a result of stay-at-home orders, on top of inaccessibility of their regular extracurriculars (e.g., dance, hockey), as contributors to their reduced physical activity. Fortunately, parents reported that outdoor activity was extremely conducive to supporting children's higher-intensity movement, even if all that children received was unstructured activity (e.g., running in an open field) for a short period of time. This is consistent with research that reports children are more inclined to be active when outdoors [30], and outdoor play spaces provide additional benefits [31] to supporting movement.

Consistent with their parents, children also reported that they believed their levels of physical activity declined during the pandemic. However, this was more frequently noted by children in the upper years (i.e., 7-12 years old). Children nearing early adolescence reported their fears about diminishing their skillset for their sport as a result of not having access to their usual environment (i.e., studio, arena). In addition, they noted that engaging in sport-related skill development at home was not as physically demanding as doing so in their typical sporting environment. However, younger children said they felt 
they were still getting into higher levels of activity during time spent at home because they could engage in sport with their parents. This finding could be a consequence of the level of sport in which the children participated, as younger children tended to be primarily involved in recreational activities rather than elite sports, or the inability of young children to accurately recall physical activity participation.

Finally, the most common facilitator for physical activity engagement that parents, and children reported engaging in during the early stages of the COVID-19 pandemic were getting active outdoors. Specifically, during the summer months, when the first wave of the pandemic was coming to an end and restrictions in Ontario slightly eased (i.e., July to August 2020), and more information regarding the safety of outdoor spaces became available (e.g., little to no risk of aerosol transmission [8];), parents reported that taking their children on hikes, playing in backyards, and exploring their neighbourhoods by going on long walks were facilitators to encouraging activity and reducing screen time. This is consistent with Dunton et al.s [17] findings, who also reported that unstructured outdoor physical activity was the most common form of movement for this cohort during the early stages of COVID-19, and Schmidt et al.'s [32] study that reported an increase in children's habitual physical activity (e.g., playing outside, gardening, cycling etc.) during COVID-related lockdowns. In addition, many children voiced their disappointment about being unable to play with their friends in the park during the initial months of the pandemic (i.e., when parks and outdoor recreation spaces were closed and gatherings were limited to individual households only), but reported that when playing sports outdoors and maintaining their physical engagement in community spaces (i.e., school playgrounds and fields) was deemed accessible by public health, it was a good strategy for them to engage in activity, practice their sport, and spend time with friends while abiding by Ontario's physical distancing rules. This is important, as research shows the important role of peers in children's physical activity [33]. Specifically, children are more likely to be active when accompanied by their friends [34], and children who report having more peers also report engaging in higher levels of activity [35]. Similarly, in the present study, children with siblings cited playing with them during Ontario's stay-at-home orders as a means to maintain activity. These findings are consistent with Kracht \& Sisson's [36] systematic review that found children with siblings to have healthier physical activity patterns compared to only children.

As children who participated ranged from 4 to 12 years of age, it is apparent that missing friends is important for children both in their early years and those nearing adolescence. This is consistent with findings from Pelletier et al's [37] qualitative study, that also found children aged 7-12 reporting negative feelings with regard to missing their peers during periods of lockdown. Moreover, children who had already returned to sport at the time of being interviewed specified that their parents helped them make the decision to return to sport, but it was also a collaborative approach. This is consistent with previous research that shows parents play an important role in facilitating children's engagement in sport, as they are the individuals responsible for payment and transportation to these sorts of events and facilities [38]. Parents reported that they asked their children if they wanted to return, or if they preferred to stay at home. However, few parents reported that they felt if their child had returned to school, returning to sport was not much different with regard to contacts and/or increasing their social bubbles. As a result, both parents and children expressed their desire and comfort to return to sport if it was deemed safe by the Ontario government.

The themes identified during the interviews with parents and children show that social connectedness and interaction with friends and coaches is essential to the maintenance of children's well-being and physical activity engagement. In addition, parents reported that having their children at home worried them about the impact of the pandemic on their children's social development and associated risks of social isolation. This is in line with other research published regarding the implications of the COVID-19 pandemic on many children [29, 39]. For example, Elliott et al. [29] found that parents noticed their children to be more irritable and frustrated due to the lack of social connectedness with others for an extended period. Additionally, research shows that increased rates of depression and anxiety among children and adolescents have been documented during the pandemic [40]. This is important to address as physical activity has been noted to reduce mental health concerns in children [2], yet we are seeing decreased rates as a result of COVID-19 [12], which are likely exacerbating social isolation and irritability, as noted by parents in the present study. More research is needed to explore how supports can be put in place in the case of future pandemics and/or stay-at-home orders to support children's physical activity and support their overall well-being.

\section{Strengths and limitations}

This study represents one of the first that captured the voices of children regarding the impact of the pandemic on physical activity, play, and sport during the pandemic. However, limitations must also be addressed. First, all participants were recruited from our larger survey-based study exploring the effects of the 
pandemic on return to play, and so some participation bias may be apparent. Second, it is important to note that all interviews were conducted between December 2020 and January 2021, approximately 9 months after the onset of the pandemic, which may have had an influence on perspectives of return to sport (i.e., compared to if interviews were conducted at the onset of the pandemic). Third, nearly all parent participants were female from urban environments, which limits the diversity and transferability of perspectives obtained through the parent interviews. Further, no children under the age of 4 participated in interviews, thus limiting the findings of our study to this younger cohort. Additionally, the present study was only focused on residents of Ontario, therefore, perspectives may vary in other provinces/territories where COVID-related restrictions were different. Finally, because participants were recruited via randomization (due to the extremely high interest expressed post-survey), and no ability to recruit a diverse sample for interviews (as their sign up was not tied to their survey responses/data), most participants were from urban environments.

\section{Conclusion}

The effects of COVID-19-related lockdowns and closures on children's physical activity and active play behaviours are evident. This study advances our knowledge of pandemic-associated impacts by sharing Ontario children's and parents' voices with regard to extended stayat-home orders and their influence on movement-related behaviours and overall wellbeing (and how they differ for parents and children). In addition, the current study sheds light on the disruptive changes to family routines as a result of the pandemic, and how these have had significant impacts on children's movement opportunities, and levels of social connectedness. This study identified barriers experienced, and facilitators used in regard to children's physical activity during COVID times, as well as the influence of the pandemic on physical activity levels and perspectives on eventual return to sport/ play. Further research is needed to unpack what type of supports can be put in place to ensure children receive enough activity if physical distancing and health measures remain in place, or in the case of additional waves of this, or another, pandemic. In addition, greater efforts are needed to ensure children's voices are heard regarding the pandemic's impacts on their activity levels and social connectedness.

\section{Abbreviations}

WHO: World Health Organisation; MVPA: Moderate-to-vigorous physical activity; REB: Research ethics board.

\section{Supplementary Information}

The online version contains supplementary material available at https://doi. org/10.1186/s12889-021-12344-w.

Additional file 1: Appendix A. Semi-Structured Interview Guide for Parent Interviews. Appendix B. Semi-Structured Interview Guide for Child Interviews.

\section{Acknowledgements}

We would like to thank all parents and children for participating in this study.

\section{Authors' contributions}

MS and PT were responsible for designing the study and were involved with the successful funding application. MS and PT led the statistical analyses, and all authors assisted with the interpretation of the results. MS and PT drafted the manuscript, and all authors read, approved, provided feedback to the final document.

\section{Funding}

This study was funded by the Social Sciences and Humanities Research Council (SSHRC) Internal Explore Grant, and supported various study procedures (e.g., tokens of appreciations for participants). LMV holds a Canadian Institutes of Health Research Fellowship Award. PT holds an Early Researcher Award from the Ministry of Research and Innovation. BAB holds a Social Sciences and Humanities Research Council of Canada Joseph-Armand Bombardier Canada Graduate Scholarship.

\section{Availability of data and materials}

The data generated and analysed during the current study is available from the corresponding author on reasonable request.

\section{Declarations}

\section{Ethics approval and consent to participate}

Ethical approval for this study and all related documents was received from the University of Western Ontario's Research Ethics Board (REB \#116331). Informed consent was obtained from all parents prior to beginning the parent interviews. Prior to child interviews, parents provided informed consent allowing their children to participate, and children were explained the study in a child-friendly manner and asked to provide verbal assent. All methods were carried out in accordance with relevant guidelines and regulations.

\section{Consent for publication}

Not applicable.

\section{Competing interests}

The authors declare no potential competing interests with respect to this research, authorship and/or publication of this work.

\section{Author details}

${ }^{1}$ Health and Rehabilitation Sciences Program, Faculty of Health Sciences, University of Western Ontario, London, Ontario, Canada. ${ }^{2}$ School of Occupational Therapy, Faculty of Health Sciences, University of Western Ontario, London, Ontario, Canada. ${ }^{3}$ School of Health Studies, Faculty of Health Sciences, University of Western Ontario, London, Ontario, Canada. ${ }^{4}$ Children's Health Research Institute, Lawson Health Research Institute, London, Ontario, Canada. ${ }^{5}$ Department of Geography, Faculty of Social Sciences, University of Western Ontario, London, Ontario, Canada.

Received: 1 September 2021 Accepted: 23 November 2021

Published online: 13 December 2021

References

1. Felfe C, Lechner M, Steinmayr A. Sports and Child Development. PLoS One. 2016;11(5):e0151729 Available from: https://pubmed.ncbi.nlm.nih. gov/27144474. 
2. Carson V, Lee E-Y, Hewitt L, Jennings C, Hunter S, Kuzik N, et al. Systematic review of the relationships between physical activity and health indicators in the early years (0-4 years). BMC Public Health. 2017;17(5):854. https://doi.org/10.1186/s12889-017-4860-0.

3. Poitras VJ, Gray CE, Borghese MM, Carson V, Chaput J-P, Janssen I, et al. Systematic review of the relationships between objectively measured physical activity and health indicators in school-aged children and youth. Appl Physiol Nutr Metab. 2016;41 (6 Suppl. 3):S197-239 Available from: http://www.nrcresearchpress.com/doi/10.1139/apnm-2015-0663.

4. Tremblay MS, Carson V, Chaput J-P, Connor Gorber S, Dinh T, Duggan M, et al. Canadian 24-hour movement guidelines for children and youth: an integration of physical activity, sedentary behaviour, and sleep. Appl Physiol Nutr Metab. 2016;41(6):S311-27 Available from: https://pubmed. ncbi.nlm.nih.gov/27306437/.

5. Carlsson E, Ludvigsson J, Huus K, Faresjo M. High physical activity in young children suggests positive effects by altering autoantigen-induced immune activity. Scand J Med Sci. 2016;26(4):441-50 Available from: https://www.lib.uwo.ca/cgi-bin/ezpauthn.cgi?url=http://search.proqu est.com/docview/1774731724?accountid=15115.

6. World Health Organization. Coronavirus (COVID-19) events as they happen. 2021. Available from: https://www.who.int/emergencies/diseases/ novel-coronavirus-2019/events-as-they-happen [cited 13 Sep 2021]

7. Government of Canada. List of Acts and Regulations - Canada.ca. 2021. Available from: https://www.canada.ca/en/public-health/corporate/ mandate/about-agency/acts-regulations/list-acts-regulations.html [cited 13 Sep 2021]

8. Government of Ontario. COVID-19 (coronavirus) in Ontario. 2021. Available from: https://covid-19.ontario.ca/. [cited 13 Sep 2021]

9. de Lannoy L, Rhodes RE, Moore SA, Faulkner G, Tremblay MS. Regional differences in access to the outdoors and outdoor play of Canadian children and youth during the COVID-19 outbreak. Can J Public Heal. 2020;111(6):988-94. https://doi.org/10.17269/s41997-020-00412-4.

10. Chaput J-P, Colley RC, Aubert S, Carson V, Janssen I, Roberts KC, et al. Proportion of preschool-aged children meeting the Canadian 24-Hour Movement Guidelines and associations with adiposity: results from the Canadian Health Measures Survey. BMC Public Health. 2017;17(S5):829 Available from: http://ovidsp.ovid.com/ovidweb.cgi?T=JS\&PAGE=refer ence\&D $=$ emexa\&NEWS $=N \& A N=621886197$

11. Rhodes RE, Spence JC, Berry T, Faulkner G, Latimer-Cheung AE, O'Reilly $\mathrm{N}$, et al. Parental support of the Canadian 24-hour movement guidelines for children and youth: prevalence and correlates. BMC Public Health. 2019:19(1):1385. https://doi.org/10.1186/s12889-019-7744-7.

12. Moore SA, Faulkner G, Rhodes RE, Brussoni M, Chulak-Bozzer T, Ferguson LJ, et al. Impact of the COVID-19 virus outbreak on movement and play behaviours of Canadian children and youth: a national survey. Int J Behav Nutr Phys Act. 2020;17(1):85. https://doi.org/10.1186/ s12966-020-00987-8.

13. Bates LC, Zieff G, Stanford K, Moore JB, Kerr ZY, Hanson ED, et al. COVID-19 Impact on Behaviors across the 24-Hour Day in Children and Adolescents: Physical Activity, Sedentary Behavior, and Sleep. Child (Basel, Switzerland). 2020;7(9):138 Available from: https://pubmed.ncbi.nlm.nih.gov/32947 805.

14. Pietrobelli A, Pecoraro L, Ferruzzi A, Heo M, Faith M, Zoller T, et al. Effects of COVID-19 Lockdown on Lifestyle Behaviors in Children with Obesity Living in Verona, Italy: A Longitudinal Study. Obesity (Silver Spring). 2020;28(8):1382-5 Available from: https://www.ncbi.nlm.nih.gov/pmc/ articles/PMC7267384/pdf/nihms-1600690.pdf.

15. Guan H, Okely AD, Aguilar-Farias N, Del Pozo CB, Draper CE, El Hamdouchi $A$, et al. Promoting healthy movement behaviours among children during the COVID-19 pandemic. Lancet Child Adolesc Heal. 2020;4(6):416-8 Available from: https://pubmed.ncbi.nlm.nih.gov/32458805/.

16. Xiang M, Zhang Z, Kuwahara K. Impact of COVID-19 pandemic on children and adolescents' lifestyle behavior larger than expected. Prog Cardiovasc Dis. 2020;63(4):531-2.

17. Dunton GF, Do B, Wang SD. Early effects of the COVID-19 pandemic on physical activity and sedentary behavior in children living in the U.S. BMC Public Health. 2020;20(1):1351. https://doi.org/10.1186/ s12889-020-09429-3.

18. Riazi NA, Wunderlich K, Gierc M, Brussoni M, Moore SA, Tremblay MS, et al. "You Can't Go to the Park, You Can't Go Here, You Can't Go There":
Exploring Parental Experiences of COVID-19 and Its Impact on Their Children's Movement Behaviours. 2021. https://doi.org/10.3390/children80 30219.

19. Guba EG, Lincoln YS. Fourth generation evaluation. London: Sage; 1989.

20. Doyle S. Member checking with older women: A framework for negotiating meaning. Health Care Women Int. 2007;28(10):888-908.

21. Korstjens I, Moser A. Series: Practical guidance to qualitative research. Part 4: Trustworthiness and publishing. Eur J Gen Pract. 2018;24(1):120-4. https://doi.org/10.1080/13814788.2017.1375092.

22. Anderson C. Presenting and evaluating qualitative research. Am J Pharm Educ. 2010;74(8):141. https://doi.org/10.5688/aj7408141.

23. Braun V, Clarke V. Using thematic analysis in psychology. Qual Res Psychol. 2006:3(2):77-101.

24. Schumm WR. Confirmation bias and methodology in social science: an editorial. Marriage Fam Rev. 2021;57(4):285-93. https://doi.org/10.1080/ 01494929.2021.1872859.

25. Mitra R, Cantello ID, Buliung RN, Faulkner GEJ. Children's activity-transportation lifestyles, physical activity levels and social-ecological correlates in Toronto, Canada. J Transp Health. 2017;6:289-98 Available from: https:// www.sciencedirect.com/science/article/pii/S2214140516303036.

26. Zenic N, Taiar R, Gilic B, Blazevic M, Maric D, Pojskic H, et al. Levels and Changes of Physical Activity in Adolescents during the COVID-19 Pandemic: Contextualizing Urban vs. Rural Living Environment. Appl Sci 202010. Available from: https://www.mdpi.com/2076-3417/10/11/3997

27. Mitra R, Moore SA, Gillespie M, et al. Healthy movement behaviours in children and youth during the COVID-19 pandemic: Exploring the role of the neighbourhood environment. Health Place. 2020;65:102418. https:// doi.org/10.1016/j.healthplace.2020.102418.

28. Nigg C, Oriwol D, Wunsch K, Burchartz A, Kolb S, Worth A, et al. Population density predicts youth's physical activity changes during Covid-19 - Results from the MoMo study. Health Place. 2021;70:102619. https://doi. org/10.1016/j.healthplace.2021.102619.

29. Elliott S, Drummond MJ, Prichard I, Eime R, Drummond C, Mason R. Understanding the impact of COVID-19 on youth sport in Australia and consequences for future participation and retention. BMC Public Health. 2021;21(1):448. https://doi.org/10.1186/s12889-021-10505-5.

30. Truelove S, Bruijns BA, Vanderloo LM, O'Brien KT, Johnson AM, Tucker P. Physical activity and sedentary time during childcare outdoor play sessions: A systematic review and meta-analysis. Prev Med (Baltim). 2018;108:74-85. https://doi.org/10.1016/j.ypmed.2017.12.022.

31. Tremblay MS, Gray C, Babcock S, et al. Position Statement on Active Outdoor Play. Int J Environ Res Public Health. 2015;12(6):6475-6505. https:// doi.org/10.3390/ijerph120606475

32. Schmidt SCE, Anedda B, Burchartz A, Eichsteller A, Kolb S, Nigg C, et al. Physical activity and screen time of children and adolescents before and during the COVID-19 lockdown in Germany: a natural experiment. Sci Rep. 2020;10(1):1-12. https://doi.org/10.1038/s41598-020-78438-4.

33. Salvy SJ, Roemmich JN, Bowker JC, Romero ND, Stadler PJ, Epstein LH. Effect of peers and friends on youth physical activity and motivation to be physically active. J Pediatr Psychol. 2009;34(2):217-25.

34. Barkley JE, Salvy S-J, Sanders GJ, Dey S, Von Carlowitz K-P, Williamson ML. Peer influence and physical activity behavior in young children: An experimental study. J Phys Act Health. 2014;11(2):404-9 Available from: http://journals.humankinetics.com/doi/10.1123/jpah.2011-0376 [cited 26 Oct 2018 Oct].

35. Beets MW, Vogel R, Forlaw L, Pitetti KH, Cardinal BJ. Social support and youth physical activity: The role of provider and type. Am J Health Behav. 2006;30(3):278-89.

36. Kracht CL, Sisson SB. Sibling influence on children's objectively measured physical activity: a meta-analysis and systematic review. BMJ Open Sport Exerc Med. 2018;4(1) Available from: https://www.lib.uwo.ca/cgi-bin/ ezpauthn.cgi?url=http://search.proquest.com/docview/2081944645? accountid=15115.

37. Pelletier CA, Cornish K, Sanders C. Children's Independent Mobility and Physical Activity during the COVID-19 Pandemic: A Qualitative Study with Families. International Journal of Environmental Research and Public Health. 2021;18(9):4481. https://doi.org/10.3390/ijerph18094481.

38. Allender S, Cowburn G, Foster C. Understanding participation in sport and physical activity among children and adults: a review of qualitative studies. Health Educ Res. 2006;21 (6):826-35 Available from: https://www. 
lib.uwo.ca/cgi-bin/ezpauthn.cgi?url=http://search.proquest.com/docvi ew/199489882?accountid=15115.

39. Singh S, Roy D, Sinha K, Parveen S, Sharma G, Joshi G. Impact of COVID-19 and lockdown on mental health of children and adolescents: A narrative review with recommendations. Psychiatry Res. 2020;293:113429 Available from: https://pubmed.ncbi.nlm.nih.gov/32882598.

40. Marques de Miranda D, da Silva AB, Sena Oliveira AC, Simoes-E-Silva AC How is COVID-19 pandemic impacting mental health of children and adolescents? Int J Disaster Risk Reduct IJDRR. 2020;51:101845 Available from: https://www.ncbi.nlm.nih.gov/pmc/articles/PMC7481176/.

\section{Publisher's Note}

Springer Nature remains neutral with regard to jurisdictional claims in published maps and institutional affiliations.

- fast, convenient online submission

- thorough peer review by experienced researchers in your field

- rapid publication on acceptance

- support for research data, including large and complex data types

- gold Open Access which fosters wider collaboration and increased citations

- maximum visibility for your research: over $100 \mathrm{M}$ website views per year

At BMC, research is always in progress.

Learn more biomedcentral.com/submissions 